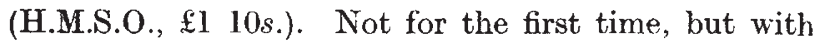
more persistence than is their custom, members of Parliament are seeking closer control of the details of university administration in Britain. Their present interest, the nub of the new report, is that the Comptroller and Auditor-General should be given regular access to the books of British universities. The committee insists that it is concerned only with seeing that public money is spent without impropriety, and it is understandable that anxiety on this score should have grown in the past two decades, during which the scale of public support for universities has multiplied fiftyfold to $£ 211$ million in the present academic year. But the fallacy is that even the candle-counting operation which the parliamentarians hanker for is inseparable from unwarrantable and necessarily ill. informed interference with academic matters.

The difficulty of separating accountability for detailed expenditure from policy issues should by now be thoroughly familiar. Under the British system, accountability to Parliament is the responsibility of the Permanent Secretary of the department to which money is voted. But no Permanent Secretary worth his salt would shoulder the task of asking universities how they spend their money without asking at the same time for their reasons. To attempt to behave differently would be at once futile and an assault on the view that, in the control of public expenditure, old-fashioned book-keeping should be replaced by more modern techniques of management. In the process, the Department of Education and Science would be caught up in enquiries into the uses made of particular equipments and buildings, and a great deal of detailed policy would have to be decided in Curzon Street, not in the universities. But this is not what Parliament wants. The public interest requires a continuing assurance that public money is well spent, but the University Grants Committee exists to provide just that. Parliament and the Department of Education and Science have a right to press for closer and more professional study of the ways in which universities make policy decisions and use the facilities with which they are equipped. They should also be encouraged by progress in the past eighteen months. But there is no case for more direct control of university administration. The example of the University of California should be a salutary example of the trouble that can bring.

\section{READY TO GO}

ThE Zuckerman committee (see page 325) has emerged a more healthy looking creature than seemed likely and even possible only a few weeks ago. By most tests, it is a strong committee. Its members are able, experienced and influential. It is particularly pleasing that the committee now formed includes several members of the Council for Scientific Policy, for that is at once an assurance that the expertise which Sir
Harrie Massey's committee has built up in the past two years will not be overlooked, and at the same time an assurance that the new committee will not be tempted to spend its time ferreting out generalizations about the research councils and the administration of civil science as a whole, for this is the part of the spectrum in which there is least to be unhappy about. Whether, in the long run, the advisory council will be able to become the particular kind of representative body which the Prime Minister seemed to have in mind right at the beginning is another matter. Because it is a Cabinet committee, its members must be appointed and not elected by the societies which they might be held to represent. It follows, of course, that the Zuckerman committee can claim to represent the scientific community as a whole only to the extent that its members command respect-which they do. This is, of course, the best arrangement, because both the committee-men and the learned societies are then free to say what they think. Since it is by no means beyond the bounds of possibility that the advisory council and the learned societies may one day find themselves at odds, this is a point well worth remembering.

But what will the advisory council advise on? And what kind of advice will it be tempted to give? As yet there are only the most fleeting hints of what may turn out to be possible. Much will depend on how quickly the committee can win for itself, within the government machine, the right to have a say about the important decisions which are being made by the Ministries of Defence and Technology. As luck will have it, the past week or so has provided several examples of matters which affect the pattern of scientific effort in the United Kingdom, and which seem to have been determined-not necessarily wronglywithout a detailed appreciation of all the consequences. The Anglo-French project for building a variable geometry military aircraft for the mid-seventies is a case in point. Mr. Denis Healey, the Minister of Defence, arrived in London from Paris with the assertion that the decision to commit $£ 250$ million to this project "will be a tonic to the aircraft industry", and so it seemed. But is it really wise to spend this sum of money, and a similar amount in France, on an option to keep in being aircraft manufacturing capacity which may never be profitable? If there is a case for thinking that Britain, or Europe, may one day make money by selling aircraft, might it not have been better to build something even more advanced than a Mach 3 aircraft ? Or would it be better to invest in computers or hovercraft instead? Perhaps the most important need is to inform decisions about technical matters by government departments with an appreciation of the economics of innovation. There is also valuable work to be done in redeploying the skilled manpower now employed and often under-employed in government establishments. By chance, the advisory council may be helped in its work by the refreshing realism which the Ministry of Technology seems to have brought to technical decision making in the past few weeks. 